\title{
Depletion of G9a gene induces cell apoptosis in human gastric carcinoma
}

\author{
XIAOLEI LIN ${ }^{1}$, YIQUN HUANG ${ }^{1}$, YONG ZOU $^{1}$, XINGSHENG CHEN $^{2}$ and XUDONG MA ${ }^{1}$ \\ ${ }^{1}$ Zhangzhou Affiliated Hospital of Fujian Medical University, Zhangzhou, Fujian 363000; \\ ${ }^{2}$ United Hospital of Fujian Medical University, Fuzhou, Fujian 350001, P.R. China
}

Received December 11, 2015; Accepted January 12, 2016

DOI: 10.3892/or.2016.4692

\begin{abstract}
G9a is a mammalian histone methyltransferase that contributes to the epigenetic silencing of tumor suppressor genes. Evidence suggests that G9a is required to maintain the malignant phenotype, but little documentation show the role of G9a function in mediating tumor growth. We retrospectively analyzed the protein of G9a and monomethylated histone $\mathrm{H} 3$ lysine 9 ( $\mathrm{H} 3 \mathrm{~K} 9 \mathrm{mel}$ ), and dimethylated histone H3 lysine 9 (H3K9 me2) in 175 cases of gastric carcinoma by immunohistochemistry. RNAi-based inhibition of G9a in MGC803 cancer cell line was studied. G9a depletion was done by transient transfection using Lipofectamine 2000. Depletion efficiency of G9a was tested using real-time PCR and western blot analysis. Cell apoptosis and proliferation were detected by TUNEL assay and MTT, respectively. The proteins of $\mathrm{H} 3 \mathrm{~K} 9 \mathrm{me1}$, me2, trimethylation of $\mathrm{H} 3 \mathrm{~K} 9$ (H3K9 me3), monomethylated histone H3 lysine 27 (H3K27 me1), dimethylated histone $\mathrm{H} 3$ lysine 27 (H3K27 me2) and histone acetylated $\mathrm{H} 3$, apoptotic proteins were studied by western blot analysis. G9a and H3K9 me2 expression was higher in gastric cancer cells compared to the control $(\mathrm{P}<0.05)$. Both $\mathrm{G} 9 \mathrm{a}$ and H3K9 me2 were positively correlated with the degree of differentiation, depth of infiltration, lymphatic invasions and tumor-node-metastasis stage in gastric carcinoma, $(\mathrm{P}<0.05)$. RNAi-mediated knockdown of G9a induced cell apoptosis and inhibited cell proliferation. Depletion of G9a reduced the levels
\end{abstract}

Correspondence to: Professor Xudong Ma, Department of Hematology, Zhangzhou Affiliated Hospital of Fujian Medical University, Zhangzhou, Fujian 363000, P.R. China

E-mail: maxudong005@hotmail.com

Abbreviations: H3K9 me1, monomethylated histone H3 lysine 9; H3K9 me2, dimethylated histone $\mathrm{H} 3$ lysine 9; H3K9 me3, trimethylation of $\mathrm{H} 3 \mathrm{~K} 9$; H3K27 me1, monomethylated histone $\mathrm{H} 3$ lysine 27; H3K27 me2, dimethylated histone H3 lysine 27; TNM, tumor-node-metastasis; HMT, histone methyltransferases; GLP, G9a-like protein; DNMT, DNA methyltransferase

Key words: gastric carcinoma, histone methylation, G9a, siRNA interference of H3K9 me1 and me2, H3K27 me1 and me2. Nonetheless, it did not activate acetylation of $\mathrm{H} 3$ and $\mathrm{H} 3 \mathrm{~K} 9$ me3. These data suggest that G9a is required in tumorigenesis, and correlated with prognosis. Furthermore, G9a plays a critical role in regulating epigenetics. Depletion of G9a inhibits cell growth and induces cells apoptosis in gastric cancer. It might be of therapeutic benefit in gastric cancers.

\section{Introduction}

Methylation of several conserved lysine residues on histone $\mathrm{H} 3$ and $\mathrm{H} 4$ tails by histone methyltransferases (HMTs) plays a key role in chromatin structure and gene regulation. The role of HMTs in promoting tumorigenesis and the progression of human cancers has begun to emerge. Methylation of H3K9 is generally associated with heterochromatin and gene repression and is a docking site for HP1 (1-3). Histone lysine methylation is mediated by HMT, many of which contain a conserved SET [Su(var)3-9, Enhancer of zeste, Trithorax] domain, such as Suv39h1 (suppressor of variegation 39h1) and G9a (4,5). Suv39h1 belongs to a family of peri-centromeric proteins and is responsible for $\mathrm{H} 3 \mathrm{~K} 9$ trimethylation (6-9). G9a is the major methylase responsible for mono- and di-methylation of H3K9 and H3K27 euchromatic regions $(10,11)$, but it may also be present in heterochromatic regions (12). G9a plays an important role in the silencing and subsequent de novo DNA methylation of embryonic and germ-line genes during normal development and is necessary for the maintenance of the DNA methylation profile of mammalian cells $(13,14)$. G9a and G9a-like protein (GLP) are the primary HMTs responsible for histone H3 lysine 9 methylation in euchromatic DNA (11).

Aberrant histone methylation has not been well characterized in human disease, especially in gastric carcinoma. The function of G9a is still not well known. In the present study, we characterized the G9a, H3K9 mel and H3K9 me2 expression in gastric carcinoma tissue, evaluated the correlation between G9a, H3K9 me2 and the clinicopathological features, in gastric carcinoma. Furthermore, we applied the siRNA technique to deplete G9a and measured consequent histone methylation in H3K 9 me1, me2 me3 and H3K27 me1 and H3K27 me2 and histone acetylation of $\mathrm{H} 3$, cell proliferation and apoptosis in MGC-803 cells to characterize the function of G9a in gastric carcinoma. 
Table I. Clinical significance of G9a and H3K9 me2 expression in gastric carcinoma $(\mathrm{n}=175)$.

\begin{tabular}{|c|c|c|c|c|c|c|c|c|c|}
\hline \multirow[b]{2}{*}{ Group } & \multirow[b]{2}{*}{$\mathrm{n}$} & \multicolumn{4}{|c|}{ G9a expression } & \multicolumn{4}{|c|}{ H3K9 me2 } \\
\hline & & Positive & Negative & $\chi^{2 / t}$ & P-value & Positive & Negative & $\chi^{2 / t}$ & P-value \\
\hline \multicolumn{10}{|l|}{ Gender } \\
\hline Male & 133 & 113 & 20 & 2.2 & $>0.05$ & 120 & 13 & 0.06 & $>0.05$ \\
\hline Female & 42 & 40 & 2 & & & 38 & 4 & & \\
\hline \multicolumn{10}{|l|}{ Age (years) } \\
\hline$<60$ & 67 & 54 & 13 & 2.97 & $>0.05$ & 62 & 5 & 1.01 & $>0.05$ \\
\hline$\geq 60$ & 109 & 99 & 10 & & & 96 & 13 & & \\
\hline \multicolumn{10}{|l|}{ Pathological type } \\
\hline Papillary & 20 & 17 & 3 & 2.46 & $>0.05$ & 18 & 2 & 2.86 & $>0.05$ \\
\hline Tubular & 92 & 81 & 11 & & & 85 & 7 & & \\
\hline Poor-differention & 28 & 24 & 4 & & & 25 & 3 & & \\
\hline Signet-ring & 9 & 8 & 1 & & & 7 & 2 & & \\
\hline Mucinous & 26 & 23 & 3 & & & 23 & 3 & & \\
\hline \multicolumn{10}{|l|}{ Differentiation } \\
\hline Intermediate-high & 103 & 84 & 19 & 6.62 & $<0.05$ & 88 & 15 & 5.43 & $<0.05$ \\
\hline Poor & 72 & 69 & 3 & & & 70 & 2 & & \\
\hline \multicolumn{10}{|l|}{ Depth infiltration } \\
\hline $\mathrm{T} 1+\mathrm{T} 2$ & 47 & 33 & 14 & 15.25 & $<0.05$ & 36 & 11 & 11.67 & $<0.05$ \\
\hline $\mathrm{T} 3+\mathrm{T} 4$ & 128 & 120 & 8 & & & 122 & 6 & & \\
\hline \multicolumn{10}{|l|}{ Lymph metastasis } \\
\hline No & 26 & 18 & 8 & 7.35 & $<0.05$ & 20 & 6 & 4.56 & $<0.05$ \\
\hline Yes & 149 & 135 & 14 & & & 138 & 11 & & \\
\hline \multicolumn{10}{|l|}{ TNM stage } \\
\hline I+II & 81 & 66 & 15 & 3.89 & $<0.05$ & 68 & 13 & 4.33 & $<0.05$ \\
\hline III+IV & 94 & 87 & 7 & & & 89 & 5 & & \\
\hline
\end{tabular}

Papillary, papillary adenocarcinoma; Tubular, tubular adenocarcinoma; Poor-differention, poorly-differentiated adenocarcinoma; Signet-ring, Signet-ring cell carcinoma; mucinous, mucinous adenocarcinoma.

\section{Materials and methods}

Collection of patient samples and data. There were 175 gastric carcinoma patients who underwent curative surgical resection at the Surgical Department of Zhangzhou Affiliated Hospital of Fujian Medical University between January 2001 and December 2011. None of these patients received chemotherapy or radiotherapy before the operation. Tumor specimens were collected in ten percent formalin and then embedded in paraffin for histopathological analysis. All cases were independently classified by two experienced pathologists as gastric carcinoma according to classification of the World Health Organization. The criteria of the TNM staging system were used to classify clinical pathological factors and clinical stages of gastric cancer (defined by the International Union Against Cancer TNM classification of malignant tumors, seventh Edition, 2009). All the patients gave signed informed consent. The gastric carcinoma cases consisted of 133 men and 42 women with a mean age of 63 (range, 41-84) at the time of operation. A summary of patient characteristics and pathological characteristics is presented in Table I. Patient samples from chronic superficial gastritis $(n=30)$, chronic atrophic gastritis $(n=30)$ and moderate-severe atypical hyperplasia $(n=30)$ were used as control. The research was approved by the Ethics Committee of Zhangzhou Affiliated Hospital of Fujian Medical University.

Tissue microarray construction and immunohistochemistry. Immunohistochemical studies on G9a, H3K9 me1, and H3K9 me2 were performed on formalin-fixed, paraffin-embedded tissue sections obtained from the aforementioned patients with gastric carcinoma and tissue microarrays. The primary antibodies were used rabbit monoclonal G9a antibody (1:500 dilutions; Upstate Biotechnology, Inc., Lake Placid, NY, USA), H3H9me1, H3H9me2 antibodies (1:500 dilutions; Upstate Biotechnology). A representative tumor section paraffin block (donor block) was collected from each case, and two tissue cores ( $2 \mathrm{~mm}$ in diameter) were obtained using a trephine apparatus. Because gastric carcinoma frequently shows histological heterogeneity, we sampled duplicate tissue cores from 
separate areas in individual paraffin-embedded gastric tumors for better representation of the tumor. Trephinated paraffin tissue cores were then arranged in a new recipient paraffin block (tissue array block). Cores containing tumor in $>50 \%$ of the area were considered adequate. Immunohistochemical staining was performed using commercial polyclonal rabbit anti-histone antibodies to HMT G9a, H3K9 mel and H3K9 me2. Tissue array blocks were section at a thickness of $4 \mu \mathrm{m}$ and mounted on precoated glass slides. The sections were deparaffinized and hydrated prior to immunohistochemistry. The immunohistochemical S-P method was performed according to the manufacturer's protocol. Tissues positive for all the purchased antibodies were used as positive controls, sections prepared with phosphate-buffer saline instead of the primary antibody were used as negative controls. Positive control exhibited brown color in the nuclei. The staging was scored by two independent investigators without knowledge of patient outcomes. The sections were evaluated at low magnification (x100) to identify areas where G9a, H3K9 me1, H3K 9 me2 were evenly stained. Chevallier's semi-quantity system analysis was used in the calculation of immunohistochemistry results. Results are presented as the sum of scores presenting color density and the percentage of stained cells. According to color density, non-stained cells were scored as 0 , slightly stained 1 , intermediate-stained 2 , strongly stained as 3 . When the number of positive cells was $<25 \%, 25-50 \%$, or $50-75 \%$, or $>75 \%$, the immunoreactivity was scored as $1+, 2+$, $3+, 4+$, respectively. The two scores presenting color density and the number of positive cells were added for each slide. The score of 0 was negative, 1-2 was presented as,$+ 3-4$ as ++ , 5- 6 as +++ , and 7 as ++++ . If the sum of the two scores was $\leq 2$, it was considered negative staining; $>2$ was considered positive staining. The scores of each patient group were averaged.

Cell culture analyses. Cell culture studies were done using human gastric carcinoma MGC-803 cells, which were purchased from the American Type Culture Collection. Cells were maintained in 10\% fetal bovine serum, and RPMI-1640 containing L-glutamine under $37^{\circ} \mathrm{C}$, saturated humidity and $5 \% \mathrm{CO}_{2}$. Cells were subcultured every 3-5 days. The subculture of cells was performed using $0.25 \%$ trypsin to digest the attached cells for 2-3 min.

RNA interference. The approach by transient transfecting using Lipofectamine ${ }^{\mathrm{TM}} 2000$ was employed to deplete G9a gene in MGC-803 cell lines. G9a siRNA sense: 5'-UUCAGU CUCUACUAUGAUUTT-3', antisense 5'-AAUCAUAGUAG AGACUGAATT-3' were synthesized by ShanghaiGenePharma Co., Ltd. (Shanghai, China). Transfection with siRNA was performed according to the Lipofectamine 2000 manufacturer's protocol (Invitrogen, Carlsbad, CA, USA). Inducible MGC-803 cells ( $1 \times 10^{5}$ cells/well) were seeded onto 24-well plates (Corning Life Sciences, Acton, MA, USA) and transiently transfected with 0 , or 40,80 or $120 \mathrm{nmol} / 1 \mathrm{G} 9 \mathrm{a}$ siRNA. The efficiency of siG9a and non-specific scrambled siRNA was tested using real-time PCR and western blot analysis. All experiments were conducted in triplicate using independent cultures. Both total RNA and protein were extracted after 24-h transfection.
Real-time PCR for gene expression. Real-time PCR was done using RNA isolated from MGC-803 cells, using TRIzol reagent (Invitrogen) and purified using an RNeasy kit (Qiagen). The quantity and quality of RNA samples were measured by absorbance at 260 and $280 \mathrm{~nm}$. RNA samples with an A260:A280 ratio 1.8:2.0 were stored at $-80^{\circ} \mathrm{C}$ until use. cDNA synthesis was performed using an Avian Myeloblastosis virus reverse transcriptase kit, according to the manufacturer's protocol (Promega, Madison, WI, USA). $\beta$-actin was used as internal control. Primers used in PCR amplifications were: G9a forward, 5'-UUCAGUCUCUACUAUGAUUTT-3' and reverse, 5'-AUCAUAGUAGAGACUGAATT-3'; $\beta$-actin forward, 5'-CTCCTTAATGTCACGCACGATTTC-3' and reverse: 5'-CTACAATGAGCTGCGTGTGGC-3'. Amplicon size was 292 base pairs and 517 bp for G9a and $\beta$-actin, respectively. PCR reaction conditions were: $94^{\circ} \mathrm{C} 45 \mathrm{sec}, 56^{\circ} \mathrm{C}$ $1 \mathrm{~min}, 72^{\circ} \mathrm{C} 80 \mathrm{sec}$, and was repeated 30 cycles. PCR-amplified products were electrophoresed in $1.0 \%(\mathrm{w} / \mathrm{v})$ agarose gels with $1 \mu \mathrm{g} / \mathrm{ml}$ ethidium bromide. Experiments were repeated twice.

Proliferation assay. After cells were transfected with G9a siRNA, the proliferative activity was determined by the MTT method $(0.5 \mathrm{mg} / \mathrm{ml}$; Sigma). According to the manufacturer's instructions, cells were seeded into 96-well tissue culture plates at the density of $1 \times 10^{5} /$ well in triplicate for $0,24,48$, 72 and $96 \mathrm{~h}$ with different concentrations (0, 40, 60, 80, 100 or $120 \mathrm{nmol} / \mathrm{l}$ ) of G9a siRNA. The spectrophotometric absorbance of the samples was determined by using Ultra Multifunctional Microplate Reader (Tecan US, Inc., Durham, $\mathrm{NC}, \mathrm{USA}$ ) at 492 and $630 \mathrm{~nm}$ for absorbance. Suppression ratio was also calculated. The experiment was repeated in triplicate.

Apoptosis detected by TUNEL assay. Cells at logarithmic phase were transfected with negative control siRNA, and 40, 80 and $120 \mathrm{nmol} / 1 \mathrm{G} 9 \mathrm{a}$ siRNA, and were seeded in 6-well plates $\left(1 \times 10^{6}\right.$ cells/well; Costar Life Sciences) with sterile coverglass placed at the bottom of each well. After 24-h transfection, apoptotic cells were detected by TUNEL, according to the manufacturer's protocol (DeadEnd ${ }^{\mathrm{TM}}$ Fluorometric TUNEL system; Promega).

Western blot analysis. Total protein lysates and western blot analysis were performed as previously described (15). Briefly, MGC-803 cells were plated on culture dishes and transfected by G9a siRNA with 40,80 and $120 \mathrm{nmol} / \mathrm{l}$ for $24 \mathrm{~h}$. Control cells were incubated in the medium with $\mathrm{Na}_{2} \mathrm{CO}_{3}$ using the same time-points. After incubation, total proteins were prepared from each culture condition with a lysis buffer containing freshly prepared protease inhibitors. Protein concentration was then measured using BCA protein assay (Pierce, Rockford, IL, USA). Cell extracts were subjected to $12 \%$ SDS-PAGE and electrophoretically transferred to nitrocellulose membrane. Membranes were incubated with monoclonal anti-monomethyl-histone $\mathrm{H} 3 \mathrm{~K} 9$, anti-di-methyl-histone $\mathrm{H} 3 \mathrm{~K} 9$, anti-tri-methyl-histone $\mathrm{H} 3 \mathrm{~K} 9$, anti-mono-methyl-histone H3K27, anti-dimethyl-histone H3K27, anti-acetyl-histone H3, and G9a (Upstate Biotechnology), BCL-2, Bax, pro-caspase-3, (Santa Cruz Biotechnology, Santa Cruz, CA, USA). After being washed with TBS, membrane was incubated with secondary 


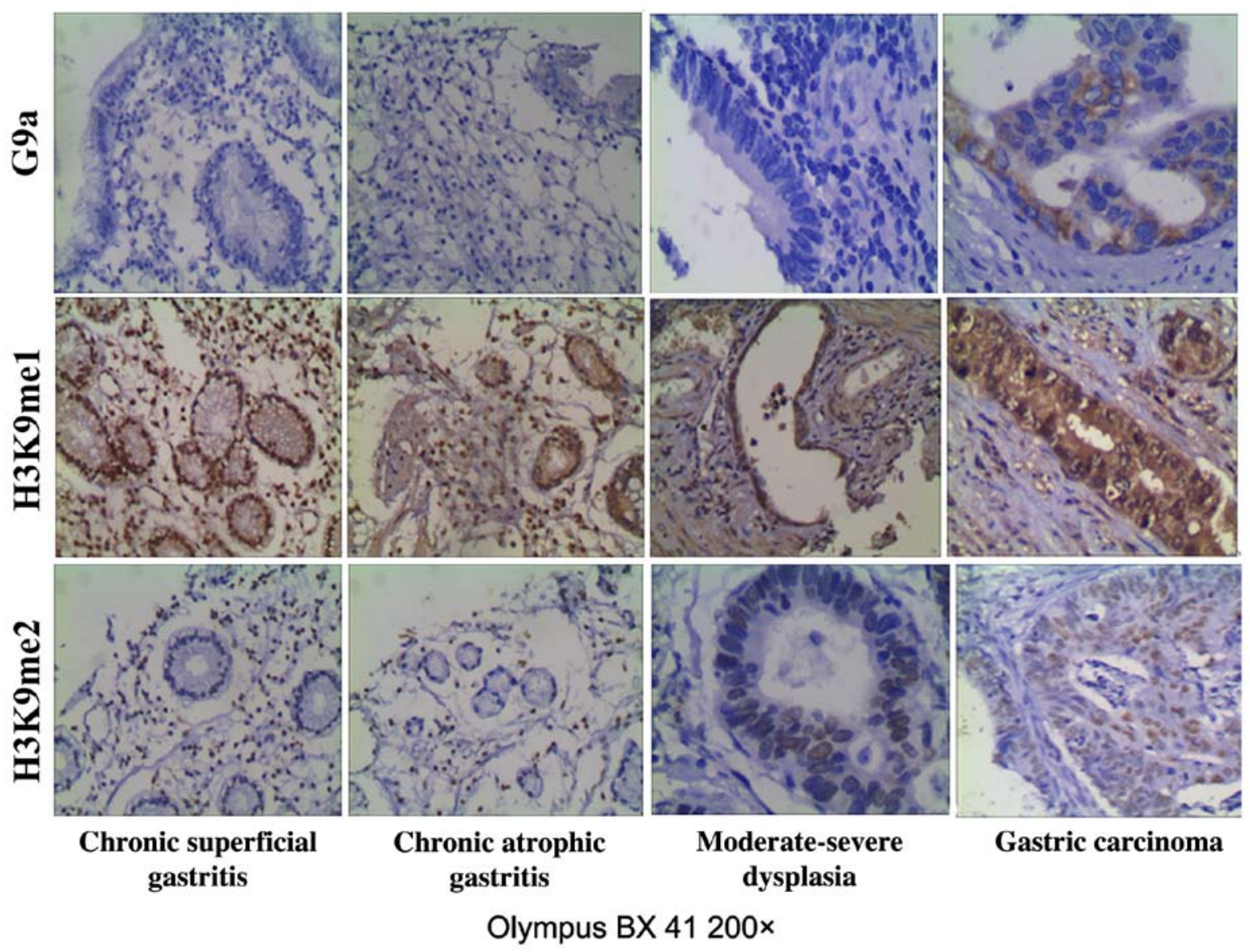

Figure 1. The expression of G9a, monomethylated H3K9 and dimethylated H3K9 in gastric carcinoma and benign gastric diseases. The expression of G9a and H3K9 me2 in gastric carcinoma was higher than that in chronic superficial gastritis, chronic atrophic gastritis and moderate-severe dysplasia, $\mathrm{P}<0.05$. The histone H3K9 me1 in gastric carcinoma was also similar, $\mathrm{P}>0.05$.

antibody conjugated with peroxidase. The signal was then detected using the chemiluminescent detection system (Pierce) and analysed by a color image analysis system (AlphaDigiDoc; Alpha Innotech, Corp., St. San Leandro, CA, USA).

Statistical analysis. The Student's t-test for mean and standard deviation, or the Mann-Whitney test for median and range were performed for comparisons between the groups in regards to continuous data. Comparisons among groups regarding categorical data were analyzed by performing the Chi-square test. All data were analyzed using the SPSS, version 16.0 computer program (SPSS, Inc., Chicago, IL, USA), and the significance of these differences was defined as $\mathrm{P}<0.05$.

\section{Results}

Overexpression of G9a, H3K9 me 2 in gastric carcinoma tissues. We found overexpression of G9a, and H3K9 me2 in gastric carcinoma tissues. The expression of G9a in gastric carcinoma was $87.43 \%$, clearly higher than that in chronic superficial gastritis $(33.33 \%, \mathrm{P}<0.05)$, chronic atrophic gastritis $(43.33 \%, \mathrm{P}<0.05)$ and moderate-severe dysplasia (46.67\%, $\mathrm{P}<0.05)$. The histone H3K9 me2 in gastric carcinoma was $90.28 \%$, higher than that in chronic superficial gastritis $(36.67 \%, \mathrm{P}<0.05)$, chronic atrophic gastritis $(40.00 \%, \mathrm{P}<0.05)$, and moderate-severe dysplasia $(56.67 \%, \mathrm{P}<0.05)$. The expres- sion of histone H3K9 mel in gastric carcinoma was 50.86\%, similar to chronic superficial gastritis $(53.33 \%, \mathrm{P}>0.05)$, chronic atrophic gastritis $(50.00 \%, \mathrm{P}>0.05)$ and moderatesevere dysplasia (56.67\%, P>0.05) (Fig. 1).

G9a and H3K9 me2 expression in gastric carcinoma is associated with poor prognosis. The association of G9a, and H3K9 me2 expression with clinical outcomes was analyzed separately. We divided the level of staining scores into two groups: negative (score $\leq 2$ ) and positive (score $>2$ ). Among these specimens, High G9a and H3K9 me2 expression positively correlated with differentiation $(\mathrm{P}<0.05)$, depth of infiltration $(\mathrm{P}<0.05)$, lymph node metastasis $(\mathrm{P}<0.05)$, and TNM stage $(P<0.05)$. They were not correlated with age $(P>0.05)$, gender $(\mathrm{P}>0.05)$ or pathological type $(\mathrm{P}>0.05)$, respectively. The relationships between the levels of G9a, and H3K9 me2 expression and the clinicopathplogical characteristics of gastric cancer are summarized in Table I.

G9a-specific siRNA inhibition of G9a in MGC-803 cells. After $24 \mathrm{~h}$ transfection with G9a siRNA of 40,80 and $120 \mathrm{nmol} / \mathrm{l}$ to MGC-803 cells, the amplification of G9a mRNA attenuated concentration dependently. Gray value (to $\beta$-actin) showed the amplification of G9a was $0.21 \pm 0.10$ with $40 \mathrm{nmol} / 1,0.11 \pm 0.04$ with $80 \mathrm{nmol} / 1$, and $0.08 \pm 0.02$ with $120 \mathrm{nmol} / 1$, respectively, compared to the control $(0.33 \pm 0.08), \chi^{2}=17.43, \mathrm{P}<0.05$. The 

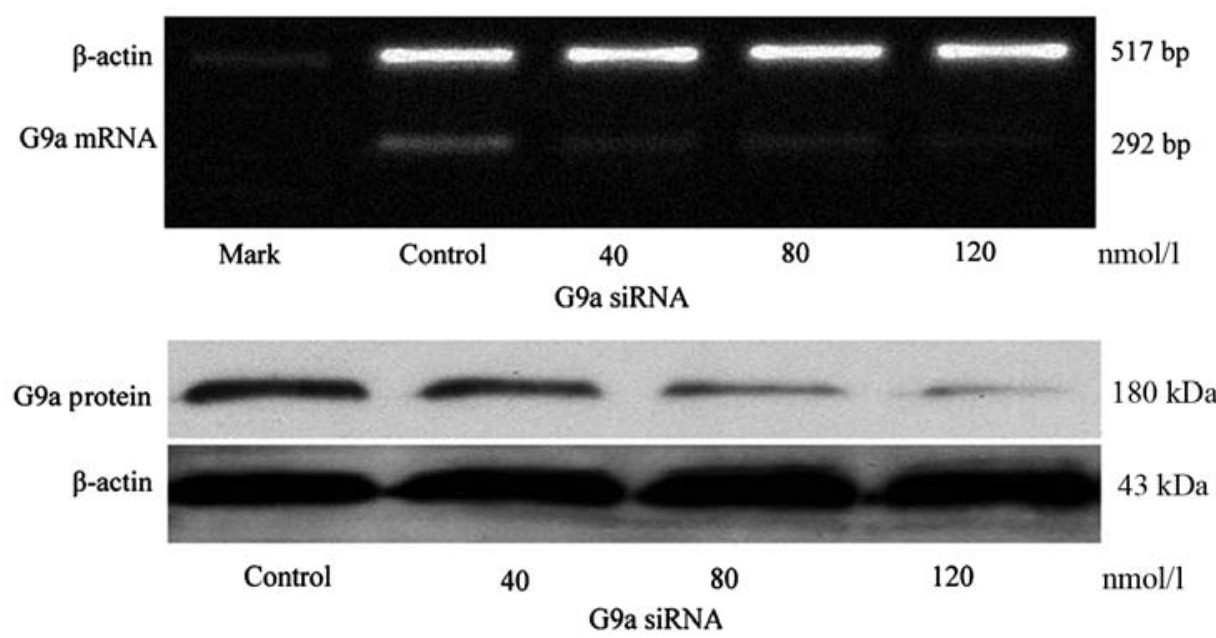

Figure 2. Silencing efficiency of G9a siRNA on G9a gene and G9a protein. Amplification of G9a mRNA and G9a protein was attenuated concentrationdependently.

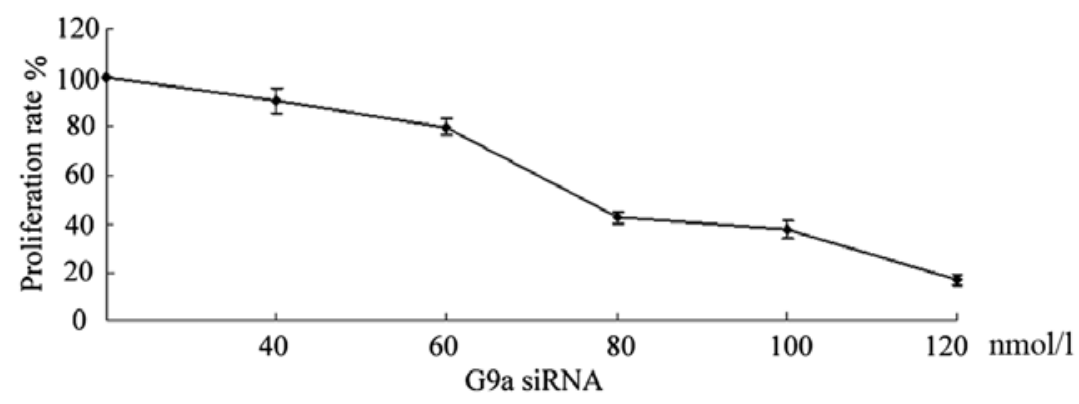

Figure 3. The observation of cell proliferation after transfected with G9a siRNA in MGC-803 cells. Cell proliferation was inhibited in MGC-803 cells after 24-h transfection of indicated concentrations of G9a siRNA.

protein of G9a also decreased concentration dependently (P<0.05; Fig. 2).

Depletion of G9a decreases cell proliferation and promotes apoptosis in MGC-803 cells. Depletion of G9a suppressed cell proliferation. To elucidate the effect of G9a on proliferation and apoptosis, G9a was knocked out by transfection of G9a siRNA in gastric cancer MGC-803 cells to exhibit cells biological changes. After 24-h transfection with G9a siRNA, $82.36 \pm 4.46 \%$ reduction in cell density was seen with $40 \mathrm{nmol} / 1,76.24 \pm 3.24 \%$ with $60 \mathrm{nmol} / 1,42.53 \pm 3.25 \%$ with $80 \mathrm{nmol} / \mathrm{l}, 17.45 \pm 1.83 \%$ with $120 \mathrm{nmol} / \mathrm{l}$ (Fig. 3). Apoptotic rate was $3.2 \pm 1.3,17.4 \pm 3.2$ and $39.7 \pm 9.2$ and $68.5 \pm 5.4 \%$ after 24-h transfection of G9a siRNA with $0,40,80$ and $120 \mathrm{nmol} / \mathrm{l}$, respectively. The apoptotic rate was increased in a concentration-dependent manner $(\mathrm{P}<0.05$; Fig. 4A). We further investigated the apoptosis-associated proteins BCL-2, procaspase- 3 and Bax. It demonstrated that G9a siRNA inhibited BCL-2, pro-caspase-3, and promoted Bax significantly, thus promoting cell apoptosis (Fig. 4B).

G9a depletion associates with reduction of the H3K9 mel, H3K 9 me 2 and histone H3K27me and H3K27 me 2 in MGC-803 cells, but not with $\mathrm{H} 3 \mathrm{~K} 9 \mathrm{me} 3$, histone acetyl H3. Lysine residues can be mono, di, or trimethylated, inducing different biological responses (16-18). The present study was performed to identify the histone modifications associated with the G9a, especially on histones methylation of $\mathrm{H} 3 \mathrm{~K} 9$ and $\mathrm{H} 3 \mathrm{~K} 27$. To this end, we transfect of G9a siRNA to gastric carcinoma MGC-803 cells and performed western blot analysis to identify the effect of depletion of G9a on histone H3K9 and H3K27 and histone acetylation of $\mathrm{H} 3$. We demonstrated that depletion of G9a for $24 \mathrm{~h}$ resulted in downregulation of histone $\mathrm{H} 3 \mathrm{~K} 9$ me1, H3K9 me2 and H3K27 me1, H3K27 me2, compared with the control. The relative (to $\beta$-actin), gray value showed H3K9 me1 was $1.21 \pm 0.19,0.84 \pm 0.17,0.42 \pm 0.14,0.19 \pm 0.08, \mathrm{H} 3 \mathrm{~K} 9 \mathrm{me} 2$ was $1.13 \pm 0.18,0.86 \pm 0.15,0.47 \pm 0.15,0.16 \pm 0.04, \mathrm{H} 3 \mathrm{~K} 27$ me was $1.01 \pm 0.12,0.82 \pm 0.11,0.51 \pm 0.14,0.31 \pm 0.07 ; \mathrm{H} 3 \mathrm{~K} 27 \mathrm{me} 2$ was $1.14 \pm 0.19,0.91 \pm 0.14,0.57 \pm 0.15,0.33 \pm 0.05$, in $0,40,80$ and $120 \mathrm{nmol} / \mathrm{l}$, respectively $(\mathrm{P}<0.05)$. There was no change in histone $\mathrm{H} 3 \mathrm{~K} 9$ me3 and histone $\mathrm{H} 3$ acetylation. The expression of $\mathrm{H} 3 \mathrm{~K} 9$ me3 was $1.08 \pm 0.17,1.11 \pm 0.16,1.09 \pm 0.17,1.07 \pm 0.16$, Act-H3 was $0.93 \pm 0.15,0.87 \pm 0.13,0.91 \pm 0.16,0.89 \pm 0.15$ in 0 , 40, 80 and $120 \mathrm{nmol} / \mathrm{l}$, respectively $(\mathrm{P}>0.05)$ (Fig. 5).

\section{Discussion}

Cancer cells are characterized by prominent epigenetic dysregulation, including altered chromatin modification. The histone methyltransferase G9a is overexpressed in a variety of cancer types, such as pancreatic adenocarcinoma, lung cancer, hepatocellular carcinoma (19-21), and promotes tumor 

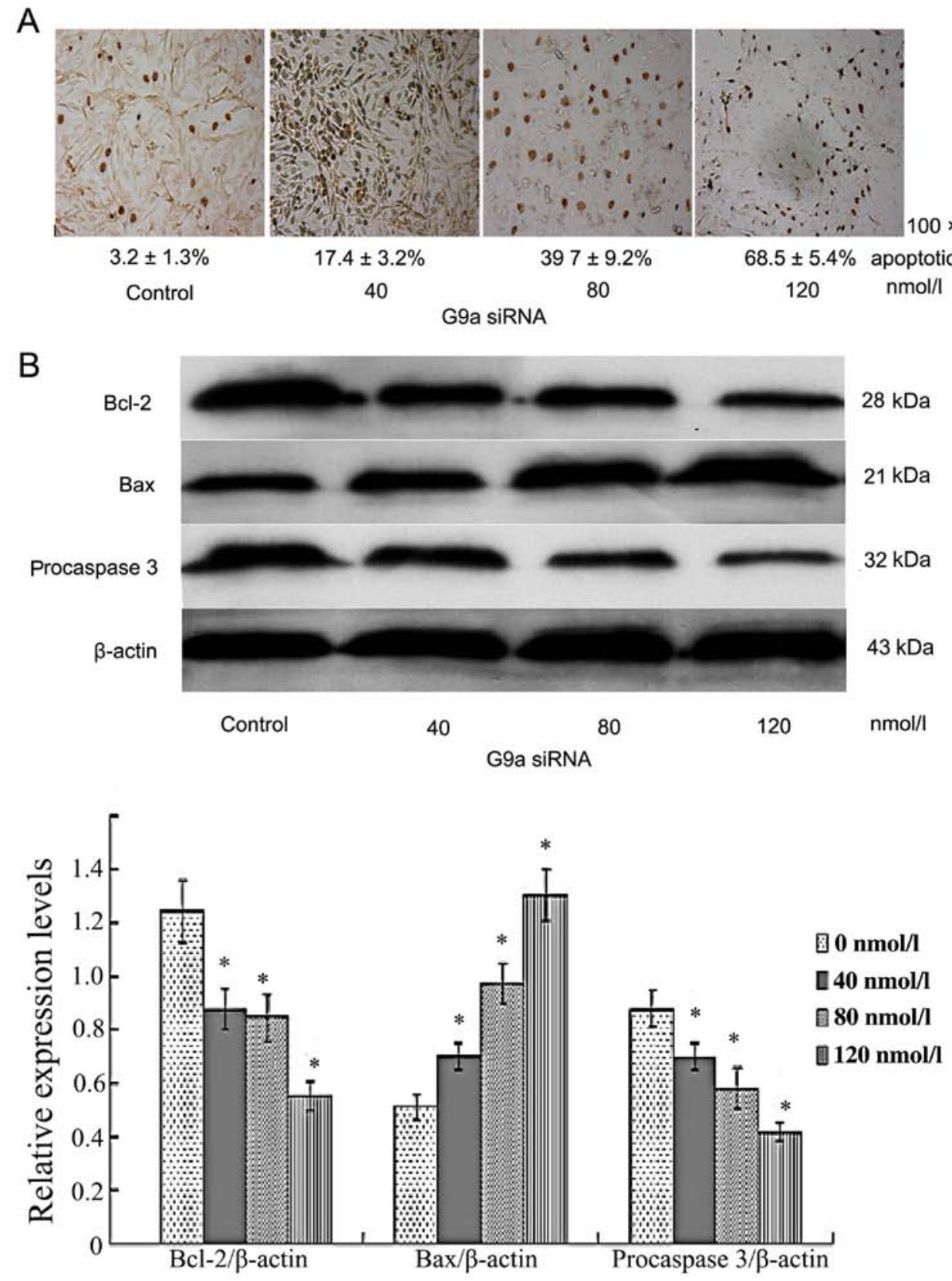

Figure 4. (A) The observation of cell apoptosis after transfected with G9a siRNA in MGC-803 cells. Cell apoptosis was induced after $24 \mathrm{~h}$ transfection with indicated concentrations of G9a siRNA in MGC-803 cells. (B) The expression of apoptosis related proteins after transfection with G9a siRNA in MGC-803 cells. The apoptosis related proteins were inhibited after $24 \mathrm{~h}$ transfection with G9a siRNA in indicated concentrations. The proteins of BCL-2, and procaspase-3 was degradated and Bax was upgradated after transfected with G9a siRNA.

invasiveness and metastasis, although the functional role of the HMTs overexpression in cancer remains unclear. Previously we found the level of SUV39H1, another HMT, was increased and associated with poor prognosis in gastric carcinoma (22). In the present study, we demonstrated that the expression of G9a, H3K9 me2 were aberrant in gastric carcinoma. The expression of $\mathrm{G} 9 \mathrm{a}, \mathrm{H} 3 \mathrm{~K} 9$ me2 in gastric carcinoma was 87.43 and $90.28 \%$, respectively, which were higher than that in the controls $(\mathrm{P}<0.05)$. Downregulation of $\mathrm{H} 3 \mathrm{~K} 9 \mathrm{mel}$ in gastric carcinoma need to be investigated. Tissue invasion and metastasis are the major causes of cancer-related death (23). The changes in global levels of individual histone modifications are independently predictive of the clinical outcome of prostate cancer, gastric adenocarcinomas, as well as breast, ovarian and pancreatic cancers (24-26). Some studies have found that HMTs specifically affect metastasis. EZH2 (the polycomb group protein enhancer of zeste homolog 2) is linked to cell proliferation and invasion in prostate and breast cancer $(27,28)$ and significantly associated with distant metastases in gastric and prostate cancer $(29,30)$. We found that G9a and H3K9 me2 were positively correlated with differentiation, depth of infiltration, lymph node metastasis and TNM stage. These results support the hypothesis that aberrant histone modification patterns are critically involved in the tumorigenetic process and indicate that G9a seems to be required for the maintenance of the malignant phenotype and could be valid therapeutic targets in human neoplasia. The elevated levels of G9a and H3K9 me2 predict poor prognosis. Chen et al (19) 

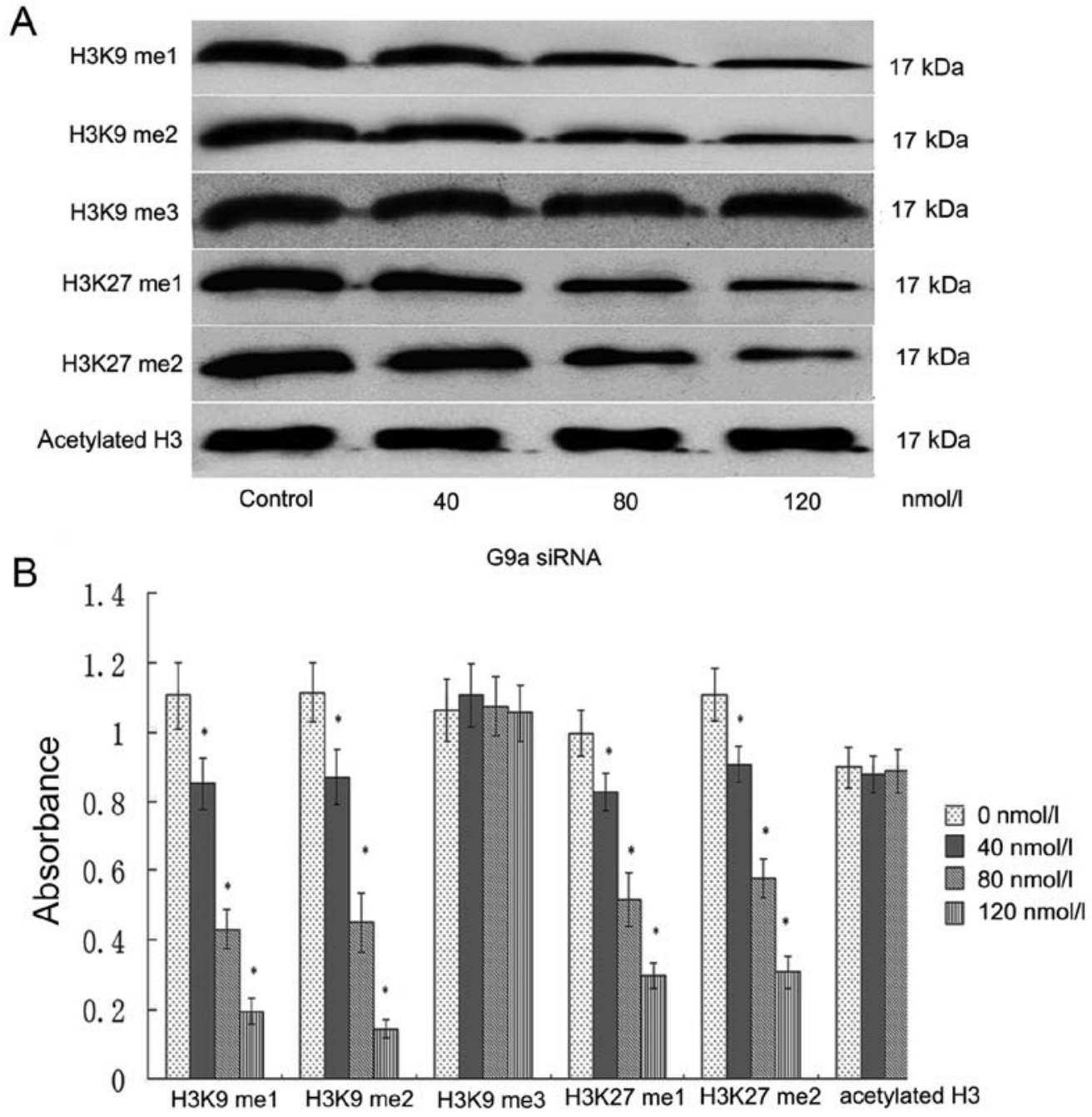

Figure 5. The expression of G9a, H3K9 me1, H3K9 me2, H3K9 me3, H3K27 me1, H3K27 me2, acetylation of H3 after 24 h transfected withG9a siRNA. The modulation of histone methylation H3K9 and H3K27 and acetylation H3 after transfected with G9a siRNA for 24 h in MGC-803 cells. G9a siRNA downregulated histone monomethylated H3K9, histone dimethylated H3K9, histone monomethylated H3K27, and histone dimethylated H3K27. Tri-methylated H3K9 and histone acetylation of $\mathrm{H} 3$ were not affected. ${ }^{*} \mathrm{P}<0.05 \mathrm{vs.} 0 \mathrm{nmol} \cdot \mathrm{l}^{-1}$

reported that G9a is endowed with methyltransferase activity to concomitantly repress the downstream effector Ep-CAM, thereby promoting the invasion step of the invasion-metastasis cascade. The possible mechanisms of G9a overexpression associated with cancer metastasis might be involved in posttranslational regulation. It is possible that high G9a expressing cells may contain more cancer stem cell potential with higher capability for metastasis.

The aberrant overexpression of G9a in gastric carcinoma may make it a good candidate as a therapeutic molecular target. We transfered G9a siRNA to MGC-803 cells and observed their biological phenomenon. The evidence showed that depletion of G9a reduced cell proliferation, and induced apoptosis in human gastric cancer cell line MGC-803, along with downregulation of pro-caspase-3, BCL-2, and significant upregulation of Bax, which are related to apoptosis pathway. It was reported that G9a is linked to aberrant silencing of several tumor-suppressor genes through $\mathrm{H} 3 \mathrm{~K} 9$ methylation and DNA CpG methylation (31-33). Current evidence suggests that H3K9 methylation and silencing of the p16ink4a tumor suppressor gene can occur before $\mathrm{CpG}$ methylation (34). G9a has been characterized as transcriptional silencer by executing mono-, di- and tri-methylation of euchromatic H3K9 as well as by promoting DNA methylation (35). Reduction of G9a expression coincided with the decrease in DNA methyltransferase (DNMT) activity and indicated a functional impact of G9a on DNMT 1 operations. It was reported that RUNX3 was downregulated by hypoxia in several gastric cancer cells and this suppression was on account of histone deacetylation and methylation (36). This interaction enhanced the catalytic activity of recombinant DNMT 1 in vitro, in the absence of any other proteins (37). Regulation of DNA methylation by G9a is independent of its catalytic activity, implying that its physical presence, but not $\mathrm{H} 3 \mathrm{~K} 9$ methylation or methylation of DNMT1, is relevant (14).

Lysine residues can be mono, di, or trimethylated, inducing different biological responses $(16,18,20)$. Thus, for example, highly condensed heterochromatic regions show a high degree of H3K9 me3, whereas euchromatic regions are preferentially enriched in mono- and dimethylated H3K9 (38). G9a and GLP are homologous HMT and mediate histones H3K9 me1 and $\mathrm{H} 3 \mathrm{~K} 9$ me2 and methylation at H3K27 (10). Studies in 
knockout mice for Suv39h1/2 and G9a revealed that G9a is mainly responsible for monomethylation and dimethylation of H3K9, whereas Suv39h1 and Suv39h2 direct trimethylation of H3K9 (39). We found that depletion of G9a decreased H3K9 me1, me2, and H3K27 me1, me2, and could not change H3K9 me3 and histone acetylation of H3. Previously studied showed that silencing Suv39H1 downregulated histone acetylated H3, H3K9 me3, and enhanced P15 in MGC-803. It did not affect H3K27, H3K14 and H4 $(22,40)$.

In conclusion, our data show that G9a and H3K9 me2 are highly expressed in gastric cancer, and associate with poor prognosis. Depletion of G9a reduces H3K9 me1, H3K9 me2, H3K27 me1, H3K27 me2, and producse tumor cell apoptosis and inhibits cell proliferation. The results from this study highlight the potential of G9a, a methyltransferase, that could be a therapeutic target for gastric carcinoma.

\section{Acknowledgements}

The present study was partly supported by grant-in-aid from the Foundation of Science and Technology of Fujian Medical University, Fujian, China (no. FZS13004Z), the Key Medical Innovations Project Science Research Foundation of Health Bureau of Fujian Provincial Health (2012-CX-32), the Science Foundation of Fujian Province (2012J01420), and the Introductive Major Project of Science Research Foundation of Fujian Province (201212004).

\section{References}

1. Bannister AJ, Zegerman P, Partridge JF, Miska EA, Thomas JO, Allshire RC and Kouzarides T: Selective recognition of methylated lysine 9 on histone H3 by the HP1 chromo domain. Nature 410: 120-124, 2001

2. Jacobs SA, Taverna SD, Zhang Y, Briggs SD, Li J, Eissenberg JC, Allis CD and Khorasanizadeh S: Specificity of the HP1 chromo domain for the methylated N-terminus of histone H3. EMBO J 20: 5232-5241, 2001.

3. Lachner M, O'Carroll D, Rea S, Mechtler K and Jenuwein T: Methylation of histone $\mathrm{H} 3$ lysine 9 creates a binding site for HP1 proteins. Nature 410: 116-120, 2001.

4. Kouzarides T: Chromatin modifications and their function. Cell 128: 693-705, 2007.

5. Schneider R, Bannister AJ and Kouzarides T: Unsafe SETs: Histone lysine methyltransferases and cancer. Trends Biochem Sci 27: 396-402, 2002.

6. Aagaard L, Schmid M, Warburton P and Jenuwein T: Mitotic phosphorylation of SUV39H1, a novel component of active centromeres, coincides with transient accumulation at mammalian centromeres. J Cell Sci 113: 817-829, 2000.

7. Aagaard L, Laible G, Selenko P, Schmid M, Dorn R, Schotta G, Kuhfittig S, Wolf A, Lebersorger A, Singh PB, et al: Functional mammalian homologues of the Drosophila PEV-modifier $\mathrm{Su}(\mathrm{var}) 3-9$ encode centromere-associated proteins which complex with the heterochromatin component M31. EMBO J 18: 1923-1938, 1999.

8. Melcher M, Schmid M, Aagaard L, Selenko P, Laible G and Jenuwein T: Structure-function analysis of SUV39H1 reveals a dominant role in heterochromatin organization, chromosome segregation, and mitotic progression. Mol Cell Biol 20: 3728-3741, 2000.

9. O'Carroll D, Scherthan H, Peters AH, Opravil S, Haynes AR, Laible G, Rea S, Schmid M, Lebersorger A, Jerratsch M, et al: Isolation and characterization of Suv39h2, a second histone H3 methyltransferase gene that displays testis-specific expression. Mol Cell Biol 20: 9423-9433, 2000.

10. Tachibana M, Sugimoto K, Fukushima T and Shinkai Y: Set domain-containing protein, G9a, is a novel lysine-preferring mammalian histone methyltransferase with hyperactivity and specific selectivity to lysines 9 and 27 of histone H3. J Biol Chem 276: 25309-25317, 2001.
11. Tachibana M, Sugimoto K, Nozaki M, Ueda J, Ohta T, Ohki M, Fukuda M, Takeda N, Niida H, Kato H, et al: G9a histone methyltransferase plays a dominant role in euchromatic histone $\mathrm{H} 3$ lysine 9 methylation and is essential for early embryogenesis. Genes Dev 16: 1779-1791, 2002.

12. Estève PO, Patnaik D, Chin HG, Benner J, Teitell MA and Pradhan S: Functional analysis of the $\mathrm{N}$ - and C-terminus of mammalian G9a histone H3 methyltransferase. Nucleic Acids Res 33: 3211-3223, 2005.

13. Dong KB, Maksakova IA, Mohn F, Leung D, Appanah R, Lee S, Yang HW, Lam LL, Mager DL, Schübeler D, et al: DNA methylation in ES cells requires the lysine methyltransferase G9a but not its catalytic activity. EMBO J 27: 2691-2701, 2008.

14. Ikegami K, Iwatani M, Suzuki M, Tachibana M, Shinkai Y, Tanaka S, Greally JM, Yagi S, Hattori N and Shiota K: Genomewide and locus-specific DNA hypomethylation in G9a deficient mouse embryonic stem cells. Genes Cells 12: 1-11, 2007.

15. Ma X, Fang Y, Beklemisheva A, Dai W, Feng J, Ahmed T, Liu D and Chiao JW: Phenylhexyl isothiocyanate inhibits histone deacetylases and remodels chromatins to induce growth arrest in human leukemia cells. Int J Oncol 28: 1287-1293, 2006.

16. Lachner M, Sengupta R, Schotta G and Jenuwein T: Trilogies of histone lysine methylation as epigenetic landmarks of the eukaryotic genome. Cold Spring Harb Symp Quant Biol 69: 209-218, 2004.

17. Jenuwein T: The epigenetic magic of histone lysine methylation. FEBS J 273: 3121-3135, 2006.

18. Santos-Rosa H, Schneider R, Bannister AJ, Sherriff J, Bernstein BE, Emre NC, Schreiber SL, Mellor J and Kouzarides T: Active genes are tri-methylated at K4 of histone H3. Nature 419: 407-411, 2002.

19. Chen MW, Hua KT, Kao HJ, Chi CC, Wei LH, Johansson G, Shiah SG, Chen PS, Jeng YM, Cheng TY, et al: H3K9 histone methyltransferase G9a promotes lung cancer invasion and metastasis by silencing the cell adhesion molecule Ep-CAM. Cancer Res 70: 7830-7840, 2010.

20. Yuan Y, Tang AJ, Castoreno AB, Kuo SY, Wang Q, Kuballa P, Xavier R, Shamji AF, Schreiber SL and Wagner BK: Gossypol and an HMT G9a inhibitor act in synergy to induce cell death in pancreatic cancer cells. Cell Death Dis 4: e690, 2013.

21. Kondo Y, Shen L, Suzuki S, Kurokawa T, Masuko K, Tanaka Y, Kato H, Mizuno Y, Yokoe M, Sugauchi F, et al: Alterations of DNA methylation and histone modifications contribute to gene silencing in hepatocellular carcinomas. Hepatol Res 37: 974-983, 2007.

22. Cai L, Ma X, Huang Y, Zou Y and Chen X: Aberrant histone methylation and the effect of Suv39H1 siRNA on gastric carcinoma. Oncol Rep 31: 2593-2600, 2014.

23. Steeg PS: Metastasis suppressors alter the signal transduction of cancer cells. Nat Rev Cancer 3: 55-63, 2003.

24. Seligson DB, Horvath S, Shi T, Yu H, Tze S, Grunstein M and Kurdistani SK: Global histone modification patterns predict risk of prostate cancer recurrence. Nature 435: 1262-1266, 2005.

25. Park YS, Jin MY, Kim YJ, Yook JH, Kim BS and Jang SJ: The global histone modification pattern correlates with cancer recurrence and overall survival in gastric adenocarcinoma. Ann Surg Oncol 15: 1968-1976, 2008.

26. Wei Y, Xia W, Zhang Z, Liu J, Wang H, Adsay NV, Albarracin C, Yu D, Abbruzzese JL, Mills GB, et al: Loss of trimethylation at lysine 27 of histone $\mathrm{H} 3$ is a predictor of poor outcome in breast, ovarian, and pancreatic cancers. Mol Carcinog 47: 701-706, 2008.

27. Ding L, Erdmann C, Chinnaiyan AM, Merajver SD and Kleer CG: Identification of EZH2 as a molecular marker for a precancerous state in morphologically normal breast tissues. Cancer Res 66: 4095-4099, 2006.

28. Bryant RJ, Cross NA, Eaton CL, Hamdy FC and Cunliffe VT: EZH2 promotes proliferation and invasiveness of prostate cancer cells. Prostate 67: 547-556, 2007.

29. Choi JH, Song YS, Yoon JS, Song KW and Lee YY: Enhancer of zeste homolog 2 expression is associated with tumor cell proliferation and metastasis in gastric cancer. APMIS 118: 196-202, 2010.

30. Min J, Zaslavsky A, Fedele G, McLaughlin SK, Reczek EE, De Raedt T, Guney I, Strochlic DE, Macconaill LE, Beroukhim R, et al: An oncogene-tumor suppressor cascade drives metastatic prostate cancer by coordinately activating Ras and nuclear factor-kappaB. Nat Med 16: 286-294, 2010.

31. Watanabe H, Soejima K, Yasuda H, Kawada I, Nakachi I, Yoda S, Naoki K and Ishizaka A: Deregulation of histone lysine methyltransferases contributes to oncogenic transformation of human bronchoepithelial cells. Cancer Cell Int 8: 15, 2008. 
32. Wozniak RJ,Klimecki WT, Lau SS, Feinstein Y and Futscher BW: 5-Aza-2'-deoxycytidine-mediated reductions in G9A histone methyltransferase and histone $\mathrm{H} 3 \mathrm{~K} 9$ di-methylation levels are linked to tumor suppressor gene reactivation. Oncogene 26: 77-90, 2007.

33. Xin ZH, Ma HL, Wu SY and Dai CH: Determination of the inhibitory activity of angiotensin-converting enzyme inhibitor captopril by high performance capillary electrophoresis. Yao Xue Xue Bao 38: 843-845, 2003 (In Chinese).

34. Bachman KE, Park BH, Rhee I, Rajagopalan H, Herman JG, Baylin SB, Kinzler KW and Vogelstein B: Histone modifications and silencing prior to DNA methylation of a tumor suppressor gene. Cancer Cell 3: 89-95, 2003.

35. Collins R and Cheng X: A case study in cross-talk: The histone lysine methyltransferases G9a and GLP. Nucleic Acids Res 38: 3503-3511, 2010.

36. Lee SH, Kim J, Kim WH and Lee YM: Hypoxic silencing of tumor suppressor RUNX3 by histone modification in gastric cancer cells. Oncogene 28: 184-194, 2009.
37. Estève PO, Chin HG, Smallwood A, Feehery GR, Gangisetty O, Karpf AR, Carey MF and Pradhan S: Direct interaction between DNMT1 and G9a coordinates DNA and histone methylation during replication. Genes Dev 20: 3089-3103, 2006.

38. Martin $C$ and Zhang Y: The diverse functions of histone lysine methylation. Nat Rev Mol Cell Biol 6: 838-849, 2005.

39. Kondo Y, Shen L, Ahmed S, Boumber Y, Sekido Y, Haddad BR and Issa JP: Downregulation of histone H3 lysine 9 methyltransferase G9a induces centrosome disruption and chromosome instability in cancer cells. PLoS One 3: e2037, 2008.

40. Czermin B, Schotta G, Hülsmann BB, Brehm A, Becker PB, Reuter $\mathrm{G}$ and Imhof A: Physical and functional association of SU(VAR)3-9 and HDAC1 in Drosophila. EMBO Rep 2: 915-919, 2001. 